\title{
Link of Nasopharyngeal Carcinoma and Epstein-Barr Virus
}

\author{
Sugiyanto ${ }^{1,2, *}$, Lina Aryati ${ }^{1}$, Fajar Adi Kusumo ${ }^{1}$, Mardiah Suci Hardianti ${ }^{3}$ \\ ${ }^{1}$ Department of Mathematics, Universitas Gadjah Mada, 55281, Yogyakarta, Indonesia. \\ ${ }^{2}$ Department of Mathematics, Universitas Islam Negeri Sunan Kalijaga, 55281, Yogyakarta, Indonesia. \\ ${ }^{3}$ Faculty of Medicine, Universitas Gadjah Mada, 55281, Yogyakarta, Indonesia. \\ Author correspondency*: \\ sugimath@yahoo.co.id
}

\begin{abstract}
Nasopharyngeal Carcinoma (NPC) is a cancer that occurs in nasopharynx which is associated with Epstein-Barr Virus (EBV). Mutation agents in nasopharyngeal neoplasms occur because of EBV infection. Transformation of B-cells due to EBV causes hormone imbalance in lymphoid cells or nasopharyngeal epithelial tissue. Rates of EBV infection have been shown to be prognostic to NPC. The basic level of EBV DNA can be used for stratification prognosis, with higher titers showing greater disease severity and worse outcomes. With mathematical models, there is a correlation between the increase in Epstein-Barr Virus and the increase in Invasive Carcinoma Cells or increase in Nasopharyngeal Carcinoma Cells.
\end{abstract}

Keywords: Nasopharyngeal Carcinoma (NPC); Epstein-Barr Virus (EBV); mathematical model; Invasive Carcinoma Cells

\section{INTRODUCTION}

The body consists of trillions of living cells. The normal cells of the body grow, divide, and die regularly. During the early years of a person's life, normal cells divide faster to allow people to grow. Once a person becomes an adult, most cells divide only to replace obsolete or dead cells to repair the lesion. (Shah et al., 2012)

Cancer begins when cells in the body part grow out of control. There are many types of cancer, but they all start because of the absence of abnormal cell growth control. (Mimi and Yuan et al., 2002)

Nasopharyngeal carcinoma (NPC) is a malignancy derived from the epithelium or mucosa and crypts that line the surface of the nasopharynx (Morrison, 2004); (Kong et al., 2010); (Lin et al., 2003). In Indonesia, nasopharyngeal carcinoma are most commonly found among malignant tumors in head and neck and age most who suffer is age 40 years and above (Adham et al., 2012); (Fachiroh et al, 2004); (Stevens, 2005). Prevalence of nasopharyngeal carcinoma in Indonesia is 4.7 / 100.000 population per year (Nurhantari et al., 2003).

The study was first written Old et al. (1966) on the link between Epstein-Barr Virus (EBV) and NPC using metallic assays hybridization dan anticomplement immunoflourescent (ACID). About $90 \%$ of the adult population has undifferentiated nasopharyngeal carcinomas (UNPC) are positive of EBV with a blood test (Zeng and Zeng, 2010). In Wu et al. (2003) person with positive EBV, the cancer will be faster than EBV negative. Many studies indicate that UNPC is always positive EBV (Lo and Huang, 2004). EBV DNA can be identified nasopharynx that the patient has NPC disease (Sheen et al., 1998). In other words, EBV is one cause of the development of nasopharyngeal cancer.

Researchers in the medical field have created categories for the development of abnormal cells. Categorization of nasopharyngeal cancer is introduced by the World Health Organization (WHO) (Zeng and Zeng, 2010). Several methods of cancer treatment have also been developed. The development of normal nasopharynx epithelium to nasopharyngeal cancer is also known as tumorigenesis model for EBV-associated nasopharyngeal carcinoma at the cellular level. On the other hand, mathematically the development of cells from normal cells, then infected with the EBV, until then into cancer cells can be modeled as a model of dynamics. The modeling will be able to see the dynamics of the development of normal cells to become cancer cells and estimated how fast the cancer cells spread. Although the development of nasopharyngeal cancer is not only affected by EBV infection, but because EBV infection is more dominant than other factors, factors other than temporary EBV infection may be neglected in mathematical modeling (Aryati et al., 2016).

\section{Nasopharyngeal Carcinoma}

Nasopharyngeal Carcinoma is a very dangerous abnormality nasopharynx epithelium. The main one of these cancers is endemic and some areas are very low incidence of this cancer (Lu et al., 2010); (Wang et al., 2011).

The hypothesis about the cause of nasopharyngeal cancer began in the early 20th century, first proposed by 
Jackson in 1901, which proposed the hypothesis that dust irritation in cork workers would damage airway epithelia. Since then the pathogenesis of nasopharyngeal cancer has been intensively studied, in particular aimed at geographical features and racial variations. In recent years many environmental and biological factors have shown a link between the risk of nasopharyngeal cancer and recent research results suggest the role of genetic and viral factors in the progression of this disease (McDermott et al., 2001).

There are three types of NPC, these are based on cancer cells under a microscope: Keratinizing squamous cell carcinoma, Non-keratinizing differentiated carcinoma and Undifferentiated carcinoma. Each type is different from one country to another. In South China, NPC are generally found to be type Undifferentiated.

Different cancers are caused by different factors. The factors that cause nasopharyngeal cancer differ from everyone. Some of the factors can be changed, such as smoking, on the contrary the factors that cause due to age, family history of cancer, cannot be changed. However, these factors do not tell much about nasopharyngeal cancer. Many people have this disease but do not know the cause. Epstein-Barr virus (EBV) infection combined with frequent exposure to environmental carcinogenic co-factors is suggested to cause NPC development (Adham et al., 2012).

\section{Ebstein-Bar Virus (EBV)}

Ebstein-Barr Virus (EBV) or other name human herpesvirus 4 (HHV-4), belongs to the family: herpes virus Subfamily: Gammaherpesvirinae (EBV), Genus: Lymphocryptovirus (EBV) (Hendrix, 2013). The adult EBV particle has a diameter of $120-180 \mathrm{~nm}$ and wraps the lipid bilayer. The primary target of cells for EBV infection is B lymphocytes (B-cells) (Hendrix, 2013). Incubation period of virus 7 to 14 days for children and adolescents is about 30 to 50 days for adults (Bale, 1999).

The particles caused by this virus are transmitted through saliva and are often incubated in 15 years during their life without symptoms.

Seroepidemiologic studies indicate that more than $90 \%$ of people in the world are infected with EBV (Hendrix, 2013).

\section{Characteristics and mechanism of Nasopharyngeal Carcinoma}

DNA is a chemical in every human cell that makes genes, a clue to how cells function. DNA usually looks like a parent because they are the source of our DNA. DNA affects more than how people see it. Some genes contain instructions to control when cells grow and divide into new cells. Viruses such as EBV also contain DNA (Chua et al., 2016). When cells are infected with viruses, viral DNA may be mixed with normal human DNA. EBV DNA can instruct nasopharyngeal cells to divide and grow in an abnormal way (Chong et al., 1996).

EBV-infected cells express several specific viral antigens for each period of infection (Lin et al., 1997). EBV latent infection is characterized by expression of Epstein-Barr Virus Nuclear Antigen-1 (EBNA-1) and EBNA-2, Latent Protein (LMP) Membrane, and Epstein Barr virus Encoded small RNAs (EBER) (Zheng et al., 2007). These proteins can interact or have homology with various body proteins such as antiapoptosis proteins, cytokines and signal transduction. Viral proteins play a role in maintaining the EBV genome in B-cells. The EBV is detected in all periods of latent infection (Liebowitz, 1994).

All nasopharyngeal epithelial cells are considered to have the same receptors so latent EBV can become active in EBV and infect any nasopharyngeal cells, without preference. In other words, it is assumed to be a random contact between the nasopharyngeal epithelial cells and the EBV virus. The population of nasopharyngeal cells is divided into six sub-populations, normal cells, dysplasia cells, EBV-infected cells, high dysplastic cells, invasive carcinoma cells. Normal cells are injured, biased due to food preservatives or tobacco. Wounded nasopharyngeal cells may progress to lowplated cells, either due to a weak immune system, resulting in no improvement in genes or apoptosis. The EBV-infected cells are infected dysplasia cells, causing the cell to become infected. The EBV-infected that do not occur apoptosis may progress into high dysplastic cells. The high dysplastic cells may progress to invasive carcinoma cells. Invasive carcinoma cells can not heal, until it ends with the death of the patient, if no treatment. This process can be explained in Figure 1.

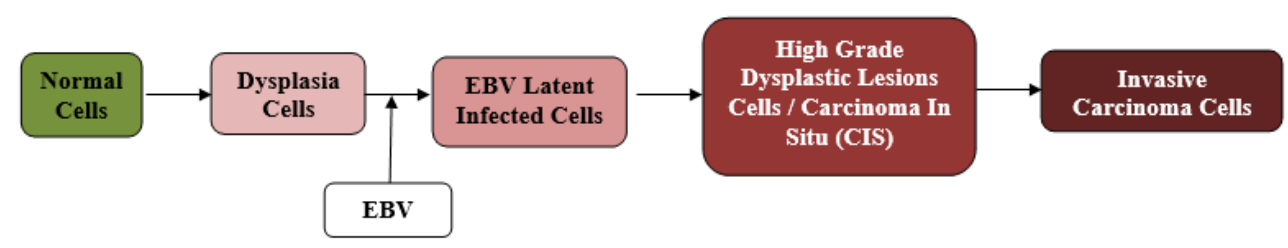

Figure 1. Tumorigenesis Nasopharyngeal Carcinoma. 
From Figure 1, system of a mathematical model (Aryati et al., 2016) in equations (1) - (6) as follows:

$$
\begin{aligned}
& \frac{d N}{d t}=a_{1}-\alpha N-d_{1} N \\
& \frac{d D}{d t}=a_{2} D+\alpha N-\beta D V-d_{2} D \\
& \frac{d I}{d t}=a_{3} I+\beta D V-\gamma I-d_{3} I \\
& \frac{d D_{H}}{d t}=a_{4} D_{H}+\gamma I-\mu D_{H}-d_{4} D_{H} \\
& \frac{d C}{d t}=a_{5} C+\mu D_{H}-d_{5} C \\
& \frac{d V}{d t}=e a_{3} I-d_{6} V
\end{aligned}
$$

where,

$$
\begin{aligned}
& N \quad \text { : Subpopulation of Normal Cells } \\
& D \quad \text { : Subpopulation of Dysplasia Cells } \\
& \text { I : Subpopulation of EBV Infected Cells } \\
& D_{H} \quad \text { : Subpopulation of High Dysplastic Cells or } \\
& \text { Carcinoma In Situ (CIS) } \\
& C \quad \text { : Subpopulation of Invasive Carcinoma Cells } \\
& V \quad: \text { Subpopulation of Viruses } \\
& a_{1} \quad: \text { The rate of proliferation of normal cells } \\
& a_{2} \quad: \text { The rate of proliferation of dysplasia cells } \\
& a_{3} \quad: \text { The rate of proliferation of EBV infected } \\
& a_{4} \quad: \text { The rate of proliferation of high dysplastic } \\
& \text { cells } \\
& a_{5} \quad: \text { The rate of proliferation of invasive } \\
& \text { carcinoma cells } \\
& d_{1} \quad: \text { The rate of apoptosis of normal cells } \\
& d_{2} \quad \text { : The rate of apoptosis of dysplasia cells } \\
& d_{3} \quad: \text { The rate of apoptosis of EBV infected cells } \\
& d_{4}: \text { The rate of apoptosis of high dysplastic cells } \\
& d_{5} \quad \text { : The rate of proliferation of invasive } \\
& \text { carcinoma cells } \\
& d_{6}: \text { The rate of apoptosis of EBV } \\
& \alpha \quad \text { : The rate of interaction between normal cells } \\
& \text { that become dysplasia cells } \\
& \beta \quad \text { : The rate of interaction between dysplasia } \\
& \text { cells that become EBV-infected cells } \\
& \gamma \quad: \quad \text { The rate of interaction between EBV-infected } \\
& \text { cells that become high dysplastic cells } \\
& \mu \quad \text { The rate of interaction between high } \\
& \text { dysplastic cells that become invasive } \\
& \text { carcinoma cells } \\
& e \quad: \text { The rate of EBV increase due to the } \\
& \text { proliferation of EBV-infected cells. }
\end{aligned}
$$

Theorem 1. The relationship between the Nasopharyngeal Carcinoma and Epstein-Barr Virus in equilibrium point is in the following equation:

$$
C=\kappa V
$$

where $\kappa=\frac{\mu \gamma d_{6}}{e a_{3}\left(d_{5}-a_{5}\right)\left(\mu+d_{4}-a_{4}\right)}$.

Proof. If $\frac{d V}{d t}=0$ and from equation (6), then it is obtained

$I=\frac{d_{6} V}{e a_{3}}$

If $\frac{d D_{H}}{d t}=0$ and from equation (4), then we get

$D_{H}=\frac{\gamma I}{\mu+d_{4}-a_{4}}$.

If $\frac{d C}{d t}=0$ and from equation (5), then we gain

$C=\frac{\mu D_{H}}{d_{5}-a_{5}}$.

If equation (8) is substituted for equation (9), then we have

$$
C=\frac{\mu \gamma I}{\left(d_{5}-a_{5}\right)\left(\mu+d_{4}-a_{4}\right)} .
$$

If equation (7) is substituted for equation (10), then it is acquired

$$
C=\frac{\mu \gamma d_{6} V}{e a_{3}\left(d_{5}-a_{5}\right)\left(\mu+d_{4}-a_{4}\right)} .
$$

From the theorem 1 that the relationship between nasopharyngeal carcinoma and Epstein-Barr Virus is affected by parameters: the rate of interaction between high dysplastic cells, the rate of interaction between EBV-infected cells that become high dysplastic cells, the rate of apoptosis of EBV, the rate of proliferation of EBV infected cells, the rate of proliferation of EBV infected cells, the rate of proliferation of invasive carcinoma cells, the rate of proliferation of invasive carcinoma cells, the rate of apoptosis of high dysplastic cells, and the rate of proliferation of high dysplastic cells. If Table 1 is included in equation 11 obtained $C=3.3 \mathrm{~V}$.

\section{Simulation}

In this section, we will discuss numerical simulations and medical interpretations of mathematical models of Nasopharyngeal Carcinoma.

Figure 2 shows a trajectory diagram for variables $\mathrm{V}$ and $\mathrm{C}$. Within 100 days, variables $\mathrm{V}$ and $\mathrm{C}$ occur at the 
beginning of the occurrence of NPC. Within the first 100 days the Epstein-Barr Virus value was 4.92 virus / $\mathrm{mm}^{2}$ and the invasive carcinoma cells value was 3.807 cell $/ \mathrm{mm}^{2}$. At the stage of the formation of invasive carcinoma cells are things that need attention, because remember this cancer is a type that is malignant. The earlier the cancer is very related to the treatment process and is related to the survival of NPC sufferers.

Figure 3 shows a portrait diagram of the phase between Epstein-Barr Virus and Invasive Carcinoma Cells. There is a correlation between the increase in Epstein-Barr Virus and Invasive Carcinoma Cells. This has an interpretation that NPC occurs because of an increase in EBV (Hu, 1996).

Table 1. The parameter values of the nasopharyngeal carcinoma mathematical model.

\begin{tabular}{|c|c|c|c|c|}
\hline No. & Parameter & Value & Unit & Reference \\
\hline 1. & $a_{1}$ & 13 & cell $\mathrm{mm}^{-3}$ day $^{-1}$ & (Huynh, 2010) \\
\hline 2. & $a_{2}$ & 0,001 & day $^{-1}$ & Estimation \\
\hline 3. & $a_{3}$ & 0.0138 & day $^{-1}$ & (Huynh, 2010) \\
\hline 4. & $a_{4}$ & 0.04 & day $^{-1}$ & (Aryati et al., 2016) \\
\hline 5. & $a_{5}$ & 0.0138 & day $^{-1}$ & (Aryati et al., 2016) \\
\hline 6. & $d_{1}$ & 1.0412 & day $^{-1}$ & (Aryati et al., 2016) \\
\hline 7. & $d_{2}$ & 0.02 & day $^{-1}$ & (Aryati et al., 2016) \\
\hline 8. & $d_{3}$ & 0.0288 & day $^{-1}$ & (Huynh, 2010) \\
\hline 9. & $d_{4}$ & 0.1152 & day $^{-1}$ & (Aryati et al., 2016) \\
\hline 10. & $d_{5}$ & 0.0188 & day $^{-1}$ & (Aryati et al., 2016) \\
\hline 11 & $d_{6}$ & 0.1152 & day $^{-1}$ & (Huynh, 2010) \\
\hline 12. & $e$ & 2 & day $^{-1}$ & (Aryati et al., 2016) \\
\hline 13. & $\alpha$ & 0.05 & day $^{-1}$ & (Aryati et al., 2016) \\
\hline 14. & $\beta$ & 1 & day $^{-1}$ & (Aryati et al., 2016) \\
\hline 15. & $\gamma$ & 0.0082 & day $^{-1}$ & (Aryati et al., 2016) \\
\hline 16. & $\mu$ & 0.07 & day $^{-1}$ & (Aryati et al., 2016) \\
\hline
\end{tabular}

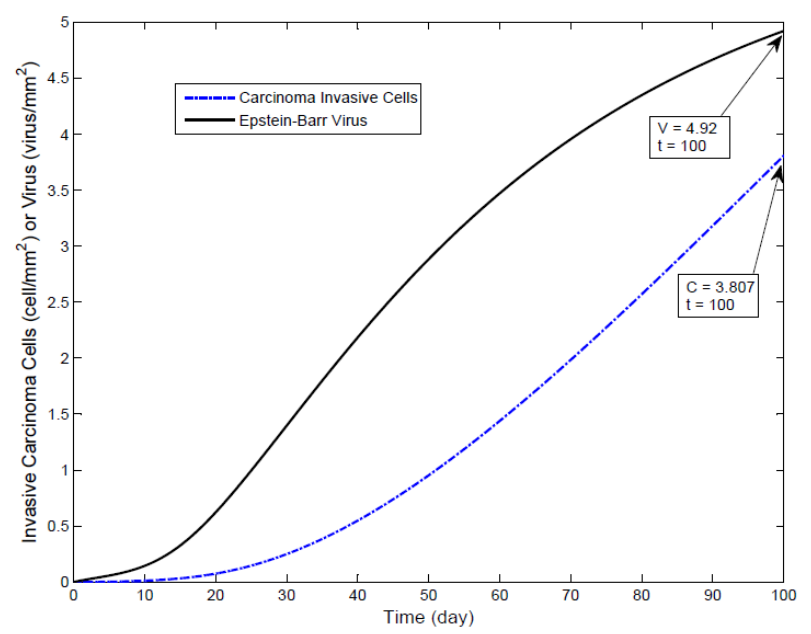

Figure 2. Trajectory diagram of Epstein-Barr Virus and invasive carcinoma cells in the first 100 days of NPC development.

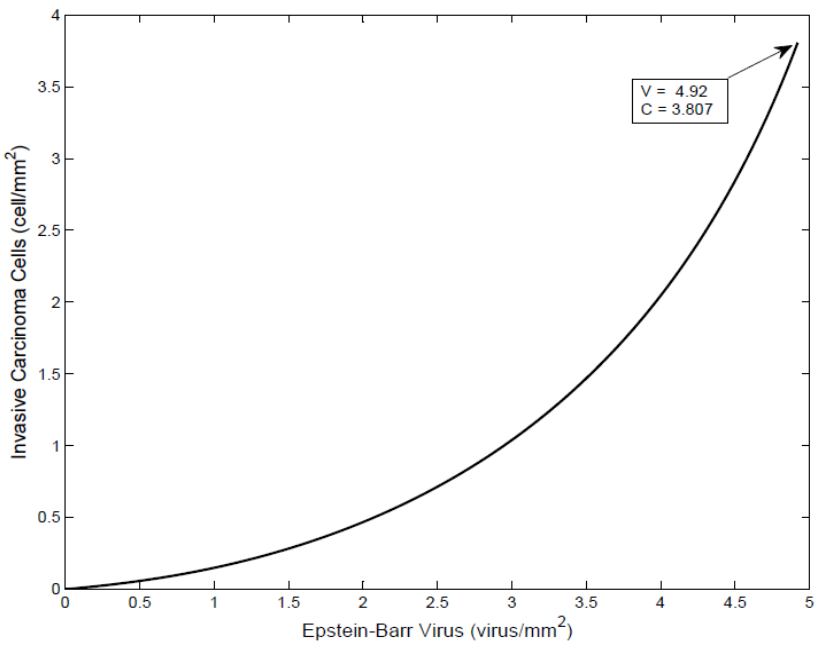

Figure 3. Portrait projection of Epstein-Barr Virus and invasive carcinoma cells in the first 100 days of NPC development.

\section{CONCLUSION}

The relationship between the Nasopharyngeal Carcinoma and Epstein-Barr Virus is directly proportional and linear. The increase in Epstein-Barr Virus makes an increase in invasive Carcinoma Cells by 3.3. In the first 100 days of development of the Nasopharyngeal Carcinoma increasing of Epstein-Barr Virus are followed Invasive Carcinoma Cells.

\section{REFERENCES}

Adham, M., Kurniawan, A. N., Muhtadi, A. I., Roezin, A., Hermani, B., Gondhowiardjo, S., ... \& Middeldorp, J. M. (2012). Nasopharyngeal carcinoma in Indonesia: epidemiology, incidence, signs, and symptoms at presentation. Chinese journal of cancer, 31(4), 185.

Aryati, L., Adi-Kusumo, F., \& Hardianti, M. S. (2016). A Cellular Mathematical Model of Nasopharyngeal Carcinoma with Addition Compartment of Virus. Far East Journal of Mathematical Sciences, 100(8), 1289.

Bale Jr, J. F. (1999, December). Human herpesviruses and neurological disorders of childhood. In Seminars in Pediatric Neurology (Vol. 6, No. 4, pp. 278-287). WB Saunders.

Chong, V. F., Fan, Y. F., \& Khoo, J. B. (1996). Nasopharyngeal carcinoma with intracranial spread: CT and MR characteristics. Journal of computer assisted tomography, 20(4), 563-569.

Chua, M. L., Wee, J. T., Hui, E. P., \& Chan, A. T. (2016). Nasopharyngeal carcinoma. The Lancet, 387(10022), 10121024.

Fachiroh, J., Schouten, T., Hariwiyanto, B., Paramita, D. K., Harijadi, A., Haryana, S. M., ... \& Middeldorp, J. M. (2004). Molecular diversity of Epstein-Barr virus $\operatorname{IgG}$ and $\operatorname{IgA}$ antibody responses in nasopharyngeal carcinoma: a comparison of Indonesian, Chinese, and European subjects. The Journal of infectious diseases, 53-62. 
Hendrix, R. (2013). Oncogenic herpesviruses: viral mechanisms and modified immune responses involved in oncogenesis (Master's thesis).

Hu, L. F. (1996). Nasopharyngeal carcinoma and epstein-barr virus.

Huynh, G. T. (2010). Mathematical Models of Epstein-Barr Virus Infection and Associated Diseases (Doctoral dissertation, Department of Mathematics, University of Utah).

Kong, Q. L., Hu, L. J., Cao, J. Y., Huang, Y. J., Xu, L. H., Liang, Y., ... \& Chen, Q. Y. (2010). Epstein-Barr virus-encoded LMP2A induces an epithelial-mesenchymal transition and increases the number of side population stem-like cancer cells in nasopharyngeal carcinoma. PLoS pathogens, 6(6), e1000940.

Liebowitz, D. (1994, June). Nasopharyngeal carcinoma: The Epstein-Barr virus association. In Seminars in oncology (Vol. 21, No. 3, pp. 376-381).

Lin, C. T., Lin, C. R., Tan, G. K., Chen, W., Dee, A. N., \& Chan, W. Y. (1997). The mechanism of Epstein-Barr virus infection in nasopharyngeal carcinoma cells. The American journal of pathology, 150(5), 1745.

Lin, J. C., Jan, J. S., Hsu, C. Y., Liang, W. M., Jiang, R. S., \& Wang, W. Y. (2003). Phase III study of concurrent chemoradiotherapy versus radiotherapy alone for advanced nasopharyngeal carcinoma: positive effect on overall and progression-free survival. Journal of clinical oncology, 21(4), 631-637.

Lo, K. W., To, K. F., \& Huang, D. P. (2004). Focus on nasopharyngeal carcinoma. Cancer cell, 5(5), 423-428.

Lu, J. J., Cooper, J. S., \& Lee, A. W. (Eds.). (2010). Nasopharyngeal cancer: multidisciplinary management. Springer Science \& Business Media.

McDermott, A. L., Dutt, S. N., \& Watkinson, J. C. (2001). The aetiology of nasopharyngeal carcinoma. Clinical Otolaryngology \& Allied Sciences, 26(2), 82-92.

Mimi, C. Y., \& Yuan, J. M. (2002, December). Epidemiology of nasopharyngeal carcinoma. In Seminars in cancer biology (Vol. 12, No. 6, pp. 421-429). Academic Press.

Morrison, J. A., Gulley, M. L., Pathmanathan, R., \& Raab-Traub, N. (2004). Differential signaling pathways are activated in the Epstein-Barr virus-associated malignancies nasopharyngeal carcinoma and Hodgkin lymphoma. Cancer research, 64(15), 5251-5260.
Nurhantari, Y., Emoto, N., Rahayu, P., \& Matsuo, M. (2003). Nasopharyngeal carcinoma in Indonesia has a low prevalence of the 30-base pair deletion of Epstein-Barr virus latent membrane protein 1. Southeast Asian journal of tropical medicine and public health, 34(1), 98-105.

Old, L. J., Boyse, E. A., Oettgen, H. F., De Harven, E., Geering, G., Williamson, B., \& Clifford, P. (1966). Precipitating antibody in human serum to an antigen present in cultured Burkitt's lymphoma cells. Proceedings of the National Academy of Sciences, 56(6), 1699-1704.

Shah, J. P., Patel, S. G., \& Singh, B. (2012). Head and neck surgery and oncology. Elsevier Health Sciences.

Sheen, T. S., Ko, J. Y., Chang, Y. L., Chang, Y. S., Huang, Y. T., Chang, Y., ... \& Hsu, M. M. (1998). Nasopharyngeal swab and PCR for the screening of nasopharyngeal carcinoma in the endemic area: a good supplement to the serologic screening. Head \& Neck: Journal for the Sciences and Specialties of the Head and Neck, 20(8), 732-738.

Stevens, S. J., Verkuijlen, S. A., Hariwiyanto, B., Fachiroh, J., Paramita, D. K., Tan, I. B., ... \& Middeldorp, J. M. (2005). Diagnostic value of measuring Epstein-Barr virus (EBV) DNA load and carcinoma-specific viral mRNA in relation to anti-EBV immunoglobulin A ( $\operatorname{IgA}$ ) and $\operatorname{IgG}$ antibody levels in blood of nasopharyngeal carcinoma patients from Indonesia. Journal of clinical microbiology, 43(7), 30663073.

Wang, H. Y., Sun, B. Y., Zhu, Z. H., Chang, E. T., To, K. F., Hwang, J. S., ... \& Lee, M. (2011). Eight-signature classifier for prediction of nasopharyngeal carcinoma survival. Journal of clinical oncology, 29(34), 4516-4525.

Wu, H. C., Lin, Y. J., Lee, J. J., Liu, Y. J., Liang, S. T., Peng, Y., ... \& Lin, C. T. (2003). Functional analysis of EBV in nasopharyngeal carcinoma cells. Laboratory investigation, 83(6), 797.

Zheng, H., Li, L. L., Hu, D. S., Deng, X. Y., \& Cao, Y. (2007). Role of Epstein-Barr virus encoded latent membrane protein 1 in the carcinogenesis of nasopharyngeal carcinoma. Cell Mol Immunol, 4(3), 185-196.

Zeng, M. S., \& Zeng, Y. X. (2010). Pathogenesis and etiology of nasopharyngeal carcinoma. In Nasopharyngeal Cancer (pp. 925). Springer, Berlin, Heidelberg. 